Hulk, A.C.J. \& L. Cornips. to appear. "Neuter gender determiners and interface vulnerability in child L2 Dutch" in: Unsworth, S., Parodi, T, Sorace, A. \& M. Young-Scholten (eds.) Paths of Development in L1 and L2 acquisition. Amsterdam: John Benjamins.

\title{
Neuter gender and interface vulnerability in child L2/2L1 Dutch
}

Aafke Hulk and Leonie Cornips

University of Amsterdam and Meertens Institute (Royal Academy of Sciences)

\begin{abstract}
We examine the acquisition of grammatical gender of the definite determiner in Dutch by bilingual children from ethnic minority communities. The results show a complete acquisition of the neuter definite determiner (and demonstrative) by monolinguals (age 9;3-10;5), whereas the bilinguals of the same age perform at chance level. This can partly be explained by the fact that the Dutch nominal gender feature has a default (non-neuter) and a specific value (neuter). Furthermore, these bilinguals are exposed to a Dutch input that is quantitatively and qualitatively different from the standard Dutch input of monolinguals. Because the Dutch input is below a certain threshold, the children's access to the right morphological form regarding grammatical gender of the definite determiner in the storage component is not optimally efficient.
\end{abstract}

\section{Introduction}

Generally, in the (generative) literature on acquisition, a clear distinction is made between children acquiring two languages from birth (2L1) and children acquiring a second language starting between age 4 and 7 (child L2), although both are sometimes called bilingual 
children. The most obvious difference between those two groups of child acquirers is the initial state of their emerging grammars. ${ }^{1}$ Whereas in $2 \mathrm{~L} 1$ acquisition the two grammars emerge simultaneously, in child L2 acquisition the emergence of the two grammars takes place successively, at least for a large part. There are, however, also important similarities between the two types of acquisition, which, strangely enough, are rarely mentioned in the literature. Most importantly, in both 2L1 and child L2 acquisition the child is supposed to have full access to UG, as opposed to what is sometimes assumed for adult L2 acquisition. In that sense, both 2L1 and child L2 acquisition are more similar to (monolingual) L1 acquisition than to adult L2 acquisition. There may be more similarities since many children acquiring two languages may be situated in a kind of learning situation that has characteristics of both 'pure' 2L1 and of child L2 acquisition, as we will discuss more extensively later with respect to 'our' bilingual subjects. The learning situation is influenced by the sociolinguistic embedding of the second language (and its speakers). For instance, the second language of a 2L1-acquiring child can be the language of the family or the surrounding minority community the child belongs to. Hence, dominance of one of the languages may exist in the input, as may language mixing. Consequently, the sociolinguistic embedding of the second language may have an effect on quality and the quantity of the linguistic input.

With respect to child L2 acquisition, the L2 grammar starts to develop at a moment when at least a (large) part of the L1 grammar is already in place. Therefore, although direct access to UG is possible, influence of the L1 grammar on the L2 grammar is to be expected, in the sense that the grammar of one language (L1) may somehow feed the emerging grammar of the other (L2). This influence is generally called 'transfer' as in adult L2 acquisition. Generally, transfer of grammatical properties will lead to a qualitative difference between the emerging L2 grammar and the target grammar. It is expected that transfer will be overcome at a certain stage of development, contrary to what is often the case in adult L2 acquisition, 
where the qualitative differences may persist and lead to what has been called 'fossilization'. As yet, little is known about the acquisition of interface phenomena in child L2 acquisition and the possible influence of the L1 in this domain. ${ }^{2}$

In the literature on 2L1 acquisition, however, interface domains play an important role, since these domains have been characterized as 'vulnerable', i.e. sensitive to cross-linguistic influence, in contrast to pure syntax. The leading idea of recent decades is that children who acquire two languages from birth separate their two languages/grammars from very early on (cf. Meisel 1989, Paradis \& Genesee 1995, De Houwer 1990 among many others). The emerging grammars develop in a very similar way to the development of the corresponding monolingual L1 grammars. Hulk and Müller (2000) and Müller and Hulk (2001), among many others, have argued that cross-linguistic influence is nevertheless possible in certain vulnerable domains and in particular in the interface domain between syntax and pragmatics. Specifically, the input from one language may temporarily feed the emerging grammar of the other language if certain conditions are met. In that case, bilingual children may prefer certain structures that are not part of the target adult grammar than monolingual children.

Monolingual children may produce the same structures in their emerging grammars but less frequently or for a much shorter time (cf. Gawlitzek-Maiwald \& Tracy 1996, Hulk et. al. 2003, Muysken 2000). This type of cross-linguistic influence in 2L1 acquisition has been characterised as 'quantitative', as opposed to the 'qualitative' influence ('transfer') which might appear in child L2 acquisition. An interesting question to be raised in this respect is whether such quantitative differences may turn into qualitative differences, and if so, under what conditions? In the present article, we take as starting point recent ideas by Sorace (2005) in order to explore this question in more depth.

Sorace (2005) has argued that interface domains present an inherent problem for acquisition since they involve the integration/co-ordination of different types of knowledge: 
the acquisition of constructions/phenomena requiring the integration of syntactic knowledge and knowledge from other domains is more complex than the acquisition of phenomena involving syntactic knowledge only. Interestingly, Sorace also discusses the role of the input in relation to such integration problems. She argues that the quantitative and qualitative differences between the input of monolinguals and bilinguals may have 'destabilizing' effects and may affect emerging grammars in different ways. She raises the interesting question of whether reduced/non-target input affects representations or processing abilities. Her hypothesis is that quantitative differences in the input are likely to affect processing abilities because of fewer opportunities to integrate syntax and other knowledge in interpretation and production, whereas qualitative differences may affect representations because of insufficient evidence for interface mappings.

In the present paper, we consider the acquisition of the gender of the definite determiner in Dutch in an exploratory cross-sectional study of bilingual children between 3 and 10 years old. Grammatical gender is particularly interesting with respect to Sorace's hypothesis since it involves the integration of both lexical, morphological and syntactic knowledge. We will discuss production data of (bilingual) children who were born and who live in the Netherlands in families which are part of (ethnic) minority communities. The members of these communities, at least in the older generations, do not speak Dutch very well. Moreover, the children attend Dutch (pre-) schools where they come into contact with many other children from their (ethnic) community with whom they (can) communicate in a language other than Dutch. Therefore, although they strictly speaking acquire two languages from birth in the sense that they are in principle exposed to input from both languages from birth onwards, it is not entirely clear, especially in the early stages, what the quality and quantity of the Dutch input, as their non-community language, has been. In this sense, we could characterise our 
subjects as being in a situation which has characteristics of both $2 \mathrm{~L} 1$ and of child L2 acquisition.

This paper is organized as follows. In section 2, we will briefly present the Dutch determiner system and consider how it - and in particular, gender morphology - is acquired by monolingual children. Sections 3 and 4 constitute the main body of this article in which our own experimental data and results are presented and discussed. In the last section, the results are interpreted in relation to the general issue of interface vulnerability and related factors.

\section{The acquisition of grammatical gender of definite determiners in Dutch}

\subsection{Gender morphology on definite determiners in Dutch}

Unlike English, Dutch makes a difference between neuter and non-neuter nouns. With the exception of diminutive nouns, which are always neuter and take the suffix $-(t) j e$, this difference is not reflected in the morphology of the noun. It is however reflected in a number of agreeing elements accompanying the noun or referring to it. Definite determiners are a clear case: singular definite determiners vary morphologically according to the gender of the noun and no variation is found in the plural determiner. Similar to definite determiners, demonstrative determiners vary morphologically according to the gender of the accompanying noun in the singular:

@@ Insert Figure 1 here 
There is no gender distinction on the singular indefinite article, which is een for both neuter and non-neuter nouns. (1) and (2) present examples of the morpholgical variation of definite determiners and demonstratives in Dutch:

(1)
a. een
tafel
de
tafel
a (NON-NEUTER) table
the (NON-NEUTER) table
b. het
tafeltje
de
tafel(tje)s
the (NEUTER) table + DIM
the (PLUR) table (DIM) PLUR
c. die/deze tafel
die/deze tafels
that/this (non-NEUTER) table
the (PLUR) table
a. een boek
het
boek
a (NEUTER) book
the (NEUTER) book
b. het boekje
de boeken
the (NEUTER) book + DIM
the (PLUR) book
c. dit/dat boek
dieldeze boeken
this/that (NEUTER) book
the (PLUR) book

(2)

Linguistically speaking, (nominal) gender in Dutch can be analyzed as an [un-interpretable] feature, whose default value is [non-neuter]. This gender feature has to combine with the $[+$ singular $]$ number feature and the [interpretable $][+$ definite $]$ feature in order to realize morphologically the specific value [neuter] on the (definite or demonstrative) determiner. Another interesting aspect of the gender specification of Dutch nouns is the relative size of the two gender classes. According to a dictionary-based estimate, roughly $75 \%$ of Dutch nouns are non-neuter (de-words) and only $25 \%$ are neuter (het-words). ${ }^{3}$ Van Berkum 
(1996) examined the relative distribution of $d e$ - and het-words in computerized databases and found that in running texts, the estimate is roughly $2: 1$, respectively. Summarizing, not only can we expect to find at least twice as much de- as het-words in a given discourse as a result of this gender bias, de will appear even more frequently because it is the determiner for both plural neuter and non-neuter nouns.

In addition to determiners, pronouns, i.e. demonstrative, personal and relative pronouns, also agree in gender with their (singular) antecedents and show morphological gender distinction. In those cases, it does not matter whether these antecedents are definite or indefinite. We will come back to relative pronouns later, but the other pronouns are left outside the scope of this article, as are attributive adjectives, which also vary morphologically according to the gender of the noun, under certain conditions. ${ }^{4}$

\subsection{The acquisition of gender morphology on definite articles by (monolingual) Dutch children}

As observed for children acquiring other languages, the first nouns monolingual Dutch children produce are bare (Chierchia et al. 2001 and references cited there). According to Bol \& Kuiken (1988), quite soon hereafter, well before their second birthday, children start to use a schwa-element which could be interpreted as the indefinite article een ('a(n)'). There is no literature on the order of emergence or frequency of occurrence of the definite article in combination with a noun, but examples of child utterances in the literature show that combinations of definite article + noun and demonstrative determiner + noun are certainly present in the first half of the third year. Van Zonneveld (1992) mentions a certain number of gender errors in definite articles in child Dutch data, all of which involve the use of the nonneuter de instead of the neuter het. According the De Houwer \& Gillis (1998:37): 
"experimental studies investigating determiner usage by somewhat older children confirm that the acquisition of syntactic gender in Dutch may be a long-drawn out process". More recently, Van der Velde $(2003,2004)$ studied the acquisition of gender morphology in articles by Dutch monolingual children between 3 and 6 years old in a cross-sectional experiment. In an experimental elicitation task, children were expected to produce article + noun sequences in both isolated contexts and inside clauses. Her results show that these children tended to overgeneralize the non-neuter definite article $d e$; that is, they used de where the neuter het is expected until age 6. What is particularly striking is that (monolingual) Dutch children overgeneralize in one direction only i.e. they use incorrectly de instead of het with neuter nouns but never the reverse. This is different from what we know of adult L2 acquisition of Dutch definite determiners since these learners make errors in both directions (Blom \& Polišenská (2005), Blom et al. work in progress). In her analysis, van der Velde (op.cit) assumes that children first adopt the un(der)specified, default value for the gender feature, i.e. non-neuter. As a result, they overgeneralize the definite determiner de and use it incorrectly with het-words, too. It is only later that the children incrementally acquire the specific value [neuter] and correctly produce the definite determiner het when it is required.

As for the literature on bilingual children, De Houwer (1990) provides an extenseive discussion of the early stages of the acquisition of Dutch by a Dutch/English bilingual child, Kate, on the basis of spontaneous production data. According to De Houwer (1990:123,125): “...50\% of all neuter nouns following a determiner or changeable adjective are treated as if they were non-neuter" and "...de is clearly overgeneralized, in the sense that it is often used in circumstances where it is non-adult-like to do so, viz. in combination with neuter nouns. This is in contrast with het, which is nearly always used in an adult-like fashion, i.e. in combination with a neuter noun...". 


\section{Experimental data from Hulk \& Cornips (in press a)}

\subsection{Methodology and subjects}

Hulk \& Cornips (in press a; henceforth H\&C) replicated an experiment by Zuckerman (2001) designed to elicit production data on the morpho-syntax of inflected verbs. The data obtained in this experiment contained nouns as well as verbs, however (see below). For the present article, we analyzed these data with respect to the production of the (gender of the) definite article of the nouns produced. It is important to keep in mind that the test was not designed to elicit determiner + noun sequences and, therefore, it can in this respect be considered as a pilot-test, to be followed by other more appropriately designed experiments in the future. Zuckerman's experiment is a sentence completion test involving 40 picture pairs and 3 picture pairs as pilot sentences. ${ }^{5}$ The experimenter first presents two pictures while producing a full co-ordinating structure. Then, the experimenter presents the pictures again using a coordination structure in which the first conjunct is produced by the experimenter and the second conjunct is truncated. The children are asked to complete the sentence and to produce a finite verb and an object. The expected answer involves either a root or a non-root sentence containing a finite verb and a definite direct object, as illustrated in the following examples: ${ }^{6}$

ROOT

Experimenter:

(3) Dit is de man die het brood snijdt en dit is de man die de tomaat snijdt. Dus deze man snijdt het brood en deze man ... 
'This is the man who cuts the bread and this is the man who cuts the tomato. So, this man cuts the bread and this man ...'

expected answer: $\quad$ snijdt de tomaat 'cuts the tomato'

NON-ROOT

Experimenter:

(4) Deze man snijdt het brood en deze man snijdt de tomaat. Dus dit is de man die het brood snijdt en dit is de man die ....

'This man cuts the bread and this man cuts the tomato. So, this is the man who cuts the bread and this is the man ...'

expected answer: die de tomaat snijdt 'the tomato cuts'

For the production of determiners, the root/non-root distinction is not important and the completion here involves the repetition of the definite article + singular noun from the first co-ordinated sentence presented by the experimenter. In total, the children had to repeat 11 singular neuter nouns requiring het and 31 singular non-neuter nouns requiring de.

Our subjects are 20 children, divided into three age groups:

@@Insert Figure 2 here 
Among the 20 children were 14 bilinguals who were born and raised in the Netherlands in ethnic families and communities where the dominant language is not Dutch, and 6 monolingual Dutch children as controls. All bilingual children were born in the Netherlands but we cannot be sure that they were raised bilingually from birth. We could qualify our subjects as being in a situation which has characteristics of both 2L1 and very early child L2 acquirers. ${ }^{7}$ We should point out that the teachers/caretakers (at pre-school) selected these children to participate in the experiment on the basis of their proficiency in Dutch. All the bilingual children in the youngest and middle age groups attend three different (pre)schools in Amsterdam and those in the the oldest group attend a school in Utrecht.

\subsection{Experimental results regarding the grammatical gender on the definite determiners}

\subsubsection{Non-neuter definite determiners}

Table 1 below presents the results of the determiner production in those cases where the input contained a non-neuter noun with the definite article $d e$. In this table, we have grouped together the answers containing a definite determiner (de or het) and the ones containing a demonstrative determiner with the same gender morphology (die/deze or dat/dit, see figure 1). ${ }^{8,9}$ The targetlike responses are given in bold.

@@Insert table 1 here

The first observation is the following. We expect the children to produce the non-neuter definite determiner de when the non-neuter noun is in the stimulus or, alternatively, to produce a bare noun. We did not expect them to produce the neuter definite determiner het since we assume that [non-neuter] is the default value of the gender feature and, therefore, it is easier to acquire and should appear earlier. This expectation is borne out: the children 
hardly produce het, whereas both bare nouns $(\varnothing)$ and nouns with the definite determiner de appear frequently. ${ }^{10}$ The cross-sectional character of the experiment involving three age groups allows us to make statements about the development in the (correct) use of $d e$ and in the decrease in bare nouns. ${ }^{11}$ Let us first consider whether the differences or similarities between the age groups and between the monolingual and bilingual children are statistically significant; because of the small numbers we used the Fisher Exact Test.

(i) Within the group of monolingual children, the youngest and middle age groups differ significantly (Fisher Exact Test, $p<.0001)$ in the correct use of $d e(63 \%$ versus $90 \%$, respectively). We interpret this significant difference as an indication of a development in the acquisition of the correct production of de between these two age groups. In addition, there is no significant development between the middle and the oldest age groups. This is not surprising since the children in the middle age group are almost targetlike, with $90 \%$ correct $d e$. Moreover, there is a decrease in the use of bare nouns that corresponds to the increase of the correct use of $d e$. Hence, the children in the youngest and the middle age groups also differ significantly (Fisher Exact Test, $p<.0001)$ in the use of bare nouns $(19 \%$ versus $1 \%)$.

(ii) Within the group of bilingual children, the youngest and middle age groups differ significantly (Fisher Exact Test, $p<.0001$ ) in the correct use of $d e(36 \%$ versus 55\%, respectively), as do the middle and oldest age groups (Fisher Exact Test, $p<.0001$ ) in the correct use of $d e$ (55\% versus $94 \%$, respectively). We interpret this as an indication of a development in the acquisition of the correct production of de from the youngest until the oldest age group. Just as within the group of monolingual children there is a corresponding, significant decrease in the use of bare nouns between all three age groups (from $44 \%$ via $24 \%$ to $4 \% ; p<.0001$ for all age groups). 
We can summarize the development in the acquisition of (the correct use of) $d e$ and the corresponding differences and similarities between monolingual and bilingual children in the following way:

- For both the monolingual and the bilingual children, there is a clear development in the acquisition of the correct use of $d e$ with a concomitant decrease in the incorrect use of bare nouns;

- $\quad$ The younger bilingual age group show a lower percentage of correct use of $d e$ and a higher percentage of bare nouns than the monolingual children. Their development continues until the oldest age group, when they reach more or less the same percentage of correct use as the monolingual children, although the latter were already at this level in the middle age group. The bilingual children thus show a delay with respect to the monolingual children in this development: in other words, there is a 'quantitative' difference between the two emerging grammars.

This delay, or quantitative difference, is not unexpected: in the literature on 2L1 acquisition (Paradis \& Genesee (1995), Hulk \& Mueller (2000), Mueller \& Hulk (2001), among others), cross-linguistic influence in the form of acceleration or delay is predicted to be possible under certain conditions. Moreover, $\mathrm{H} \& \mathrm{C}$ in press a) observed a delay in the development of finite verb placement in non-roots by these same bilingual children when compared with monolinguals.

\subsubsection{Neuter definite determiners}

Let us now consider the results of the production of the neuter definite article het by the same children. These are presented in Table 2, where definite and demonstrative determiners are once again combined again and targetlike responses are in bold. 
@@Insert table 2 here

The results in this table differ from the ones in Table 1 in several respects, as discussed in more detail below. First, in contrast to the development in the acquisition of the non-neuter determiner $d e$, the development in the correct production of the neuter determiner het is significantly different for monolingual and bilingual children. Second, monolingual and bilingual children also differ from each other in their incorrect use or, in other words, overgeneralization of the non-neuter definite determiner $d e$. Finally, they differ with respect to the decrease in bare nouns.

\section{Correct use of het}

Regarding the correct use of het, the following observations can be stated.

(i) Both monolingual and bilingual children in the youngest age group produce a low percentage of correct het, namely $11 \%$ and $13 \%$ respectively. They do not significantly differ from each other.

(ii) Within the group of monolingual children, the youngest and middle age groups differ significantly in the correct use of het (Fisher Exact Test, $\mathrm{p}<.0001 ; 11 \%$ versus $77 \%$, respectively). This indicates that there is a development in the acquisition of the correct use of het. Although the oldest groups exhibits a higher percentage of correct use than the middle age group ( $90 \%$ versus $77 \%$ ), the difference between the two groups is not significant. The high percentage of correct use of het in the oldest age group does however suggest that the monolingual children have acquired the correct use of het at this age. 
(iii) Within the group of bilingual children, there are no significant differences between the young and middle age groups (13\% versus $17 \%$, respectively), nor between the middle and old groups (17\% versus $39 \%$ ( $p>.01$ for respective age-groups). We interpret this a lack of development in the correct use of het between these age groups. Note, however, that there is a significant difference between the youngest and oldest age group (Fisher Exact Test, $p<.0003,13 \%$ versus 39\%, respectively), which could be interpreted as some form of development. Nevertheless, since the bilingual children in the oldest age group only correctly produce het in $39 \%$ of their answers we cannot conclude that have acquired this form.

(iv) The monolingual and bilingual children in the middle and oldest age groups differ significantly (Fisher Exact Test, $p<.0001$ and $p<.0044$, respectively) in the correct use of het (77\% versus $17 \%$ and $90 \%$ versus $39 \%$, respectively). (Note that this is not the case in the youngest age group, see (i) above)).

\section{Overgeneralization of the non-neuter definite determiner de}

(i) Both monolingual and bilingual children overgeneralize the non-neuter definite determiner de in the youngest age group, i.e. they produce it more often than the required neuter definite determiner het. Monolingual children overgeneralize significantly more de than the bilingual children in this age group.

(ii) Within the group of monolingual children, the overgeneralization of de significantly decreases between the youngest and the middle age group (70\% versus $14 \%$, respectively, Fisher Exact Test $p<.0001$ );

(iii) Within the group of the bilingual children there is a slight - but not significant increase in the overgeneralization of $d e(24 \%, 37 \%$, and $44 \%)$ between the three age groups. 
Decrease in the use of bare nouns

(i) In the youngest age group, monolingual and bilingual children differ significantly in the number of bare nouns produced (7\% versus 49\%, respectively, Fisher Exact Test $p<.0001)$. The monolingual children in this age group produced twice as many bare nouns when the input contained a neuter het word than when it contained a non-neuter de word (7\% versus $19 \%$, respectively).

(ii) Regarding the monolingual children, there are no significant differences between the three age groups.

(iii) Within the group of bilingual children, there is a significant decrease in the use of bare nouns between the youngest and middle age group (49\% versus $11 \%, p<.0001$ ), comparable with the decrease when the stimulus contained a non-neuter $d e$-word.

\section{Summarizing}

Both monolingual and bilingual children in the youngest age group have serious problems with het, only producing it in about $12 \%$ of the cases where it is required. (It is worth emphasizing again that this reveals a very different picture from the production of $d e$ in this age group, where respectively, $63 \%$ and $36 \%$ targetlike determiners were produced.) This raises the question of what these children do when they fail to produce het. It seems to be the case that if the youngest monolingual and bilingual children produce a definite determiner, it is the non-neuter $d e$. However, the monolingual children do this significantly more than the bilingual children ( $70 \%$ versus $24 \%$, respectively). The latter, on the other hand, use significantly more bare nouns than the former ( $49 \%$ versus $7 \%$, respectively). This suggests that the youngest bilinguals show a developmental delay, that is, they are still in an earlier developmental stage (see $\S 1.2$ ). Whereas the use of bare nouns decreases with each bilingual 
subsequent age group, the overgeneralization of non-neuter de does not. In contrast, the monolingual children do show a decrease in the overgeneralization of $d e$ with increasing age. Likewise, the monolingual children in the oldest age group have acquired the correct use of het $(90 \%)$, whereas the bilingual children only produce it at chance level (49\%). It appears that the bilingual children have severe difficulties in the acquisition of het, that is, they seem to have somehow 'fossilized' in a developmental stage where they overgeneralize the nonneuter definite article $d e$. The monolingual children also go through a stage where non-neuter $d e$ is overgeneralised (see the results of the youngest age group) but, contrary to the bilingual children, they progress beyond this overgeneralisation stage.

Taken together, the monolingual and the bilingual children appear to show a 'qualitative difference' in their emerging grammars. This is a very striking result given that, as already discussed in the introduction, previous literature has not reported qualitative differences between monolingual children and children raised bilingually from birth. In the next section, we examine in more detail two possible explanations for the difference between the monolingual and the bilingual children with respect to the acquisition of het, paying particular attention to the 'ultimate attainment' of the oldest age in the experiment.

\section{Differences between mono- and bilingual children: cross-linguistic influence or deficient input?}

\subsection{Cross-linguistic influence}

The first and maybe most obvious answer to the question about the differences between the monolingual and bilingual children is the bilingualism of the latter and, consequently, the role of the other language. This might have caused a major delay in the acquisition of the Dutch 
gender distinctions, and maybe even a (temporary) 'qualitative' difference although, as noted above, this has not been mentioned before in the literature on 2L1 acquisition (unlike child L2 acquisition - see the Introduction). Since our children seem to be in between 2L1- and child L2-acquirers in some respects, it could be the case that what we have found here is the result of cross-linguistic influence from the other language of the children on their Dutch. When we restrict ourselves to (definite) determiners, we see that the other languages of the children studied, widely vary in the way they express definite determiners. A discussion of these systems is far beyond the scope of this article. One thing we can do, however, is to divide the languages in two groups, one group where 'gender' plays a role in the nominal domain and another where it does not. We thus obtain a Gender group (French and Moroccan Arabic/Berber) and a Non-gender group including Turkish, Akan, Ewe and Sranan (see Figure 2 in §2.1). The results of this division- when the input is a de-word - show that there is a significant development between the youngest and oldest age group for both the gender and the non-gender group. Interestingly, the results - when the input is a het-word - are that the children in the youngest Non-gender group do significantly better than the others. This goes against our hypothesis (outlined above) that the other language might cause a delay. However, in the oldest age group there is no significant difference present between the Gender and the Non-gender group. Apparently, the Non-gender group has an advantage in the first stage but there is no significant development from the youngest age group onwards i.e. the Non-gender older group does not perform better than the Non-gender younger groups. The gender group, however, displays a significant development between the younger and oldest age group (1\% compared with $40 \%$, respectively). Taken together, our results do not straightforwardly support the hypothesis that children with another language where gender distinction does not play a role in the nominal domain do significantly worse than the ones where such a distinction does play a role. The results do not support the reverse hypothesis either, that is, 
the children with another language where a gender distinction plays a role in the nominal domain are no better in the oldest age group than the children without gender distinctions in their other language. ${ }^{12}$ Therefore, we cannot straightforwardly attribute the problems of our bilingual children with respect to the acquisition of the neuter gender feature are due to crosslinguistic influence. ${ }^{13}$

\subsection{The role of the input in the acquisition of neuter gender nouns}

As mentioned in the Introduction, Sorace (2005) predicts that quantitative and qualitative differences between monolingual and bilingual grammars are possible when the input is below a certain threshold. We mentioned before that monolingual children who are exposed to standard Dutch input already encounter a very low frequency of the definite determiner het (see $§ 1.1$ ). What could be the consequences of this unequal distribution of gender distinctions in the input for our bilingual children? First of all, we know from the literature that when monolingual children have problems acquiring a certain phenomenon, we can be sure that bilingual children are to be expected to encounter even larger problems. Thus, problems with the acquisition of neuter gender are to be expected. Second, it is also known that there is a quantitative difference between the input the bilingual children receive in each of their two languages and the input monolingual children are exposed to. Generally, this difference in input is assumed to have consequences for the acquisition of vocabulary/lexicon rather than for the acquisition of syntax. Interestingly, the acquisition of the gender feature as expressed in the definite determiner involves the interface between the lexicon and morpho-syntax. As we already pointed out, the input monolingual children are exposed to contains very little evidence for the neuter value of the formal, un-interpretable gender feature. The only clear evidence constitutes the definite determiner het, which is rare: it is used in the singular only 
and with just 25 percent of Dutch nouns (see Figure 1). As for bilingual children, the input of het will be even more limited, making it no doubt even harder to detect the gender feature's neuter value. The above holds only for the quantitative aspect of the input which, according to Sorace's hypothesis, would be responsible for a delay, that is to say, a quantitative difference between monolinguals and bilinguals but not a qualitative difference. In other words, a difference in representation and knowledge would be expected. Our production data seem to reflect a qualitative rather than a quantitative difference, however. Therefore, the quality of the input our bilingual children are exposed to has to be taken into consideration. These children are born in The Netherlands and raised in (ethnic) minority families within communities where the Dutch variety used in both the home and the community domain is not standard Dutch. Often, the older generations who speak this variety acquired Dutch as an adult/adolescent L2 learner in a non-instructed context. We know from sociolinguistic research that these speakers overgeneralize the determiner de in their Dutch and hardly produce the determiner het ( Cornips (2002), Cornips \& Hulk (2005) and references cited there). Therefore, we could hypothesize that the (ethnic) Dutch input our children are exposed to will also be qualitatively different from the input which monolingual Dutch children are exposed to. Without further research on the characteristics of the input which these bilingual children are exposed to, these comments remain rather speculative. All we can say here is that our data show that Sorace's hypothesis is an interesting one and, hence, worth pursuing. In the next section, we try to define the experimental results in more formal linguistic terms.

\section{Linguistic analysis}

\subsection{Morphological variability of the definite determiner}


Let us now consider the experimental results from a linguistic point of view. What does the deviant development of bilingual children and their apparent 'fossilization' mean linguistically? It is plausible to assume (in line with Van der Velde (op.cit)) that when monolinguals start to produce definite determiners, they have already acquired the [uninterpretable] gender feature, but it is still underspecified. It therefore takes the default value [non-neuter] and is spelled-out as de on all definite determiners. There is no reason to assume that monolinguals and bilinguals differ in this respect. The next developmental step shows that both mono- and bilingual children start to produce the neuter definite determiner het with neuter nouns. This suggest that they have acquired the specified value [neuter] for the relevant gender feature and that they know how to spell that out on the definite determiner. Nevertheless, in this stage, they still overgeneralize the non-neuter definite determiner $d e$ with neuter nouns.

What is important to emphasize in this respect is that the individual bilingual children reveal variability in the form of the definite determiner for one and the same neuter noun, such as meisje 'girl', as presented in Figure 3 below: ${ }^{14,15}$

@@Insert Figure 3 here

What this figure suggests is that, as far as the production of the definite determiner of the neuter noun meisje 'girl' is concerned, we can distinguish three groups within the bilingual children's individual grammars. The first group exclusively produces the default non-neuter form $d e$ and is probably in a early developmental stage where the specific [neuter] value of the gender feature has not been acquired yet. The second group produces both the non-neuter default and the specific neuter form of the definite determiner, whereas the third group exclusively produces the correct neuter form het. The second group is the most interesting one 
since the results suggest that because they correctly produce het with the neuter noun meisje 'girl' in some occurrences, these children have acquired the specific [neuter] value of the gender feature. However, at the same time, these children also produce the correct default form of the definite determiner i.e. de with the same neuter noun. This observation raises the question of whether it is plausible to assume that these children have two competing grammars for each neuter noun at this stage or whether there is another explanation for these data. It is known from the literature that the use of morpho-phonology does not match the use of syntax, that is to say, the use of morpho-phonological features may not reflect the use of formal features such as gender. It is therefore possible that the bilingual children in this stage have acquired the [neuter] value of the gender feature but, under certain conditions, they tend to use the default form de in spelling it out on the definite determiner. On such a scenario, their grammar does not show a syntactic deficit and would not be qualitatively different from the grammar of monolingual children. We then expect these bilingual children to be sensitive to syntactic properties and operations where the gender feature plays a role. Interestingly, our data also contain some information about the production of relative pronouns which vary in form according to the gender of the antecedent noun. In the next section we will consider the production of the relative pronoun in the data of our children. These data may be used to determine whether the bilingual children are indeed sensitive the syntactic reflexes of the gender feature.

\subsection{The production of relative pronouns in Dutch}

\subsubsection{The gender morphology on Dutch relative pronouns}

Relative pronouns in Dutch vary morphologically according to the gender of their singular antecedent. There is no gender variation in the plural. 
@@Insert figure 4 here

This gender variation holds both for definite and indefinite antecedents, as illustrated in (5) through (7):

(5)

Dit is de/een man

die

het brood

snijdt

this is the/a (NON-NEUTER) man who (NON-NEUTER) the bread cuts

(6) Dit is het/een meisje dat de appel eet

this is the/a (NEUTER) girl who (NEUTER) the apple eats

(7)

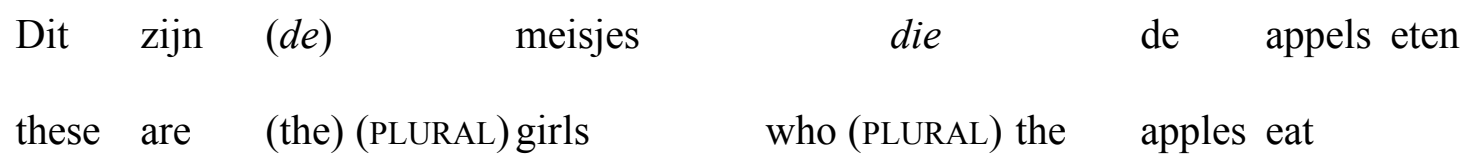

Linguistically, several operations are involved in the production of the target relative pronoun. Abstracting away from all details, we could say what is important here is first of all the syntactic operation 'Agree', which ensures that the relative pronoun agrees with its antecedent in all relevant features. Second, just as with the definite pronouns, there is the morphological spell-out of the feature bundle which reflects the default (non-neuter) and specific (neuter) values of the gender feature of the antecedent noun, as it does its number feature value, but not its definiteness.

In the production data obtained in the $\mathrm{H} \& \mathrm{C}$ experiment (in press a), relative pronouns were expected and produced only in those cases where the second conjunct was a non-root (see (4) in $\S 2.1) .{ }^{16}$ As a result, there is less data available for relative pronoun production than 
for definite article production. The test only involves one neuter noun as antecedent, e.g. dit meisje 'this girl' in 10 non-root test sentences. The other 33 sentences involved non-neuter nouns as antecedents. Contrary to what was the case for the definite determiners, the elicitation of relative pronouns did not involve a repetition of what the experimenter presented but the pronouns have to be creatively produced by the child when completing the sentence, as illustrated in (8):

Experimenter:

$$
\begin{aligned}
& \text { a. Dus dit is de } \operatorname{man}+\ldots \\
& \text { so this is the man [non-neuter] }
\end{aligned}
$$

Stefano:

$\begin{array}{llll}\text { b. }++ & \text { die } & \text { strijk de broek } \\ & \text { who [non-neuter] } & \text { irons the trousers }\end{array}$

\subsubsection{The non-neuter relative determiner}

Table 3 shows the results of the production of relative pronouns in those cases where the antecedent is a non-neuter noun ('a de-word'): ${ }^{17}$

@@Insert Table 3 here

Please, note that the numbers are very low here and, therefore, the results have to be considered with caution. The following tendencies can however be discerned:

(i) The monolingual and bilingual children differ significantly with respect to the correct use of the relative pronoun die only in the middle age group (proportion 1 versus .41 , 
respectively, Fisher Exact Test $p<.0001$ ), but no difference is found in the youngest or the oldest age group.

(ii) Within the group of monolingual children, there is a significant difference between the youngest and the middle group in terms of the correct use of die (proportion .51 versus 1, respectively, Fisher Exact Test $p<.0001$ ) but not between the middle and oldest age group. This suggests that the development in the acquisition of die takes place in between the youngest and middle age and that it is completed at this stage.

(iii) The bilingual children present a slightly different picture. There is a significant difference between the middle and oldest age group (proportion .41 versus .92, respectively, Fisher Exact Test $p<.0001$ ) but not between the youngest and middle age groups. This suggests that the development in the acquisition of die takes place between the middle and oldest age, and thus is delayed with respect to the monolingual children. This is exactly the same pattern that we found for the development in the acquisition of the non-neuter determiner $d e$.

\subsubsection{The neuter relative pronoun}

Table 4 below presents the results of the production of a relative pronoun in those cases where the antecedent is a neuter noun ('a het-word'):

@@Insert Table 4 here

The results are the following:

(i) Within the group of monolingual children, there is a significant difference between the youngest and middle age group (proportion .11 versus .5, respectively, Fisher Exact 
test $\mathrm{p}<.017)$. Although the difference between the middle and oldest age group is not significant, the high percentage $(83 \%)$ of correct use of dat by the oldest monolingual child suggests that she at least has completed the acquisition of het at this age. The non-significant differences between the youngest and middle age groups suggest that the acquisition of the neuter relative pronoun dat takes more time than the acquisition of non-neuter die, which appeared to be completed by the middle age group (see Table $3)$.

(ii) Regarding the bilingual children, there are no significant differences between the youngest and the middle groups, but there is a significant difference between the middle and the oldest age group (proportion 0 versus .57, respectively, Fisher Exact test $p<.0028$ ). This suggests that the acquisition of the neuter relative pronoun takes place between these two age groups and thus represents a delay compared to the monolingual children.

(iii) Although the proportion of the correct use of the neuter relative pronoun is still rather low even in the oldest age group (.57), the oldest bilinguals and monolinguals do not show statistically significant differences. This is in contrast with the correct use of the definite determiner het.

Taken together, the results indicate that the acquisition of the neuter relative pronoun by the bilingual children is slightly quicker than the acquisition of het. Concerning the oldest age group, the monolingual and bilingual groups are more similar in the acquisition of the neuter relative pronoun than in the acquisition of the neuter definite determiner, although production of both het and dat is not yet completely targetlike. Due to the small numbers, we can only speculate about the reason for the difference in acquisition between the neuter determiner het and the neuter relative pronoun dat. Assuming that this difference is real, it may be related to 
the fact that relative dat, is homophonous with the complementizer dat which introduces all clausal subordinate clauses. Before more certain conclusions can be drawn, however, more data on the acquisition of relative pronouns are needed.

It is nevertheless interesting to consider how the form of the definite determiner and the form of the relative pronoun for the same neuter noun het meisje 'the girl' are related in the emergent grammars of the bilingual children, particularly in the light of the proposed hypothesis above about the possible dissociation of syntax and morphology. The following figure presents the different grammars found and also, perhaps even more interesting, the grammars that are not found for the neuter noun meisje:

@@Insert Figure 5 here

The grammars that have only de meisje i.e. grammars 1 and 2 probably represent an early stage, which also include either the relative die (grammar 1) or die and dat (grammar 2), but never exclusively dat (grammar 8). Grammars that have only het meisje (grammars 6 and 7) have either the relatives die and dat (grammar 6) or only dat (grammar 7), but never exclusively die (grammar 9). Grammars that have both de and het meisje (grammar 3, 4 and 5) have die and/or dat as relative.

It is suggested above that it could be the case that morphology and syntax are dissociated and that although producing het implies the (syntactic) acquisition of the [neuter] value of the gender feature, $d e$ at the same time is still sometimes morphologically realized (produced) with the same noun. Importantly, the observations schematised in the figure above are at least partly compatible with this hypothesis. They thus show that the situation is even 
more complex since it could be the case that the relative pronoun itself has die as a default form which again does not necessarily reflect the presence or absence of syntactic features and therefore cannot be taken to support the hypothesis. Experimental comprehension studies are needed in order to shed light on this possible dissociation.

\section{Concluding remarks}

This paper has provided evidence that for both monolingual and bilingual children, the production of the neuter definite determine het (and the neuter relative pronoun dat) remains non-targetlike at a relatively late age, suggesting that this aspect of Dutch presents difficulties for both these groups of learners. This can partly be explained by the fact that the Dutch nominal gender feature has a default value (non-neuter) and a specific value (neuter). All children begin with the default value and thus, when they start to use definite determiners, they exclusively produce de even with neuter nouns. Ultimately, they have to acquire neuter as the specific value for a very small set of words. Moreover, neuter value is only morphologically realized in combination with the singular value of the number feature in definite determiners and relative pronouns. (Other such cases were left outside the scope of this article.) This confirms previous research on the development of gender in L1 Dutch (van der Velde op.cit.). Whereas the monolingual children in our sentence completion test showed complete acquisition in the oldest age group (age 9;3-10;5), the bilingual children in this age group performed only around or even below chance level. Since we did not test bilingual children older than 10;5 we could not establish whether development goes further after this age. Consequently, the differences between the monolingual and the bilingual children with respect to the correct production of the neuter definite determiner het can be qualified at least as 'quantitative', thus as a temporary delay, and perhaps even as 'qualitative' 
revealing a more permanent difference in representation. In this regard, two possible explanations were considered, namely (i) cross-linguistic influence and (ii) deficient input. In our admittedly rather preliminary discussion, we showed that having another language with or without gender distinctions in the nominal domain did not correlate with 'lack of success'. Hence, cross-linguistic influence is unlikely to explain the differences between the monolingual and bilingual children. The hypothesis of deficient input, based on ideas by Sorace (2005), proved to be more fruitful. From a quantitative perspective, it is plausible to assume that the frequency of het in the input of the bilingual children is very low, perhaps even below a certain threshold, the details of which have yet to be established. As for the quality of the input, we suggested that further (sociolinguistic) research has to find out whether the largely non-native Dutch used in the (ethnic) families and communities lacks the correct standard Dutch use of the neuter definite determiner het.

We also addressed the same question of whether the difference between monolingual and bilingual children's production is quantitative or qualitative, in the sense of a lack of knowledge or a mis-representation, from a slightly different, more linguistic perspective. The experimental results show that there were a number of bilingual children who produced both $d e$ and het as definite determiner for the same neuter word. This variability lead us to hypothesise that these children show a dissociation between syntax and morphology. To be more specific, we suggested that these children have acquired the correct specific neuter value of the gender feature but they have problems with its correct morphological spell-out as het on the definite determiner, which sometimes causes them to use the default form de instead. The (few) data from the production of the relative pronoun were compatible with this hypothesis. This raises many interesting questions for future research.

\section{Endnotes}


${ }^{1}$ Abstracting away from cognitive differences.

${ }^{2}$ See, however, Unsworth (2004, in press) for interesting experimental results and discussions on child L2 acquisition of interface phenomena.

${ }^{3}$ There exist a very small number of 'double gender’ words (Van Berkum 1996).

${ }^{4}$ See Blom and references cited there (http://home.hum.uva.nl/oz/eblom/curriculum.html) on the acquisition of adjective flexion in child and adult L2 Dutch.

${ }^{5}$ We added four test sentences to Zuckerman's original task.

${ }^{6}$ As pointed out to us by an anonymous reviewer, one might think that this task may lead the children to simply repeat what they hear. It is important to point out in this regard that the answers reveal certain patterns, which suggests that this is not the case. To be more specific, there are significant differences regarding the production of monolingual and bilingual children and between several age-groups within the group of monolingual and bilingual children. The results therefore show that these children do not copy exactly what they hear.

Consequently, we consider these results to constitute valid data, the trends in which raise interesting questions to be explored and further validated in future work.

${ }^{7}$ See Cornips \& Hulk (2005) for a detailed discussion of the sociolinguistic context of these children and their languages.

${ }^{8}$ The category 'other' involves, for instance, nouns with possessives or uninterpretable utterances as in (i): this is the girl who

child: $\quad++$ man 'man'

${ }^{9}$ Since demonstrative determiners show morphological gender variation in exactly the same way as definite determiners (see Figure 1), we treat them alike in Table 1, although elsewhere (cf. Hulk \& Cornips in press b), the demonstratives falls into the 'others' category.

${ }^{10}$ As the categories in Table 1 indicate, some children did produce a non-neuter demonstrative determiner instead of a non-neuter definite determiner. We leave the differences between these two determiners for future research.

${ }^{11}$ Here we will only consider the (correct) production of the non-neuter definite determiner de and demonstrative die/deze 'that'/'these', respectively. Other (interesting) results are left for further research. 
${ }^{12}$ Further research is needed whether this is related to the fact that there is no apparent (structural) overlap in the determiner systems in the sense of Hulk \& Müller (2000) in the languages under consideration, and therefore cross-linguistic influence is not expected.

${ }^{13}$ Further support for the rejection of this hypothesis can be found in the sociolinguistic literature which reports a massive overgeneralization of the definite determiner de in urban youth Dutch and in all ethnic varieties of Dutch, regardless of the (other) languages involved (cf. Cornips 2002).

${ }^{14}$ This also holds for other neuter nouns such as boek 'book' and brood 'bread'.

${ }^{15}$ There is only one Dutch child in the middle age group showing the same variability: stimulus: het meisje 'the girl'

response: de meisje het meisje

age, L1 Dutch

young, $n=2$

middle, $\mathrm{n}=1$

middle, $\mathrm{n}=2$

old, $n=1$

${ }^{16}$ Remember that the experiment was designed to elicit neither det $+\mathrm{N}$, nor relative pronouns, Therefore, the results should be treated with caution.

${ }^{17}$ The production of the relative pronoun is not included in those cases where the experimenter himself uttered the relative pronoun by accident. This happened in a relatively high percentage of the utterances $(23 \%)$.

\section{References}

Blom, E. et al. (work in progress) 'L2 verwerving van adjectivale flexie' presentation University of Amsterdam

Blom, E \& D. Polišenská (2005) 'Verbal inflection and verb placement in first and second language acquisition'. Proceedings 39th Linguistic Colloquium, Vrij Universiteit/Amsterdam.

Bol, G.W. and F. Kuiken 1988. Grammaticale analyse van taalontwikkelingsstoornissen. PhD Dissertation. University of Amsterdam. 
Chierchia, G., M.-T. Guasti, and A. Gualmini. 2001. "Nouns and Articles in Child Grammar and the Syntax/Semantics Map." Ms. University of Milan / University of Siena / University of Maryland, College Park.

Cornips, L. 2002. "Etnisch Nederlands." In Een buurt in beweging. Talen en culturen in het Utrechtse Lombok en Transvaal, H. Bennis, G. Extra, P. Muysken and J. Nortier (eds.), 285-302. Amsterdam: Aksant.

Cornips and Hulk. 2005 "Bilingual acquisition and 'fossilization' versus 'acceleration' of grammatical gender agreement of the definite article.", ms Meertens Institute/ University of Amsterdam.

Gawlitzek-Maiwald, I. and R. Tracy 1996. "Bilingual bootstrapping." In Two languages. Studies in Bilingual First and Second Language Development, Special Issue of Linguistics. N. Müller (ed.)

De Houwer, A. 1990. The acquisition of two languages from birth: a case study. Cambridge: Cambridge University Press.

De Houwer, A. and S. Gillis. 1998. The acquisition of Dutch. Amsterdam: Benjamins. Hulk, A. C. J. and L. Cornips in press a. 'The boundaries between child L2 and 2L1: DOsupport in child Dutch." In GASLA-7 Proceedings, L. Dekydtspotter and R. A. Sprouse (eds).

Hulk, A. and L. Cornips. in press b. "From quantitative to qualitative differences? An experimental study of bilingual Dutch" In Interfaces in Multilingualism: Acquisition, representation and processing, C. Lleo (ed). Hamburg Studies in Multilingualism Vol. 4. Amsterdam: John Benjamins.

Hulk, A. C. J. and N. Müller 2000. Bilingual first language acquisition at the interface between syntax and pragmatics'. Bilingualism: Language and Cognition 3 (3): 227244. 
Meisel, J. 1989. "Early differentiation of language in bilingual children." In Bilingualism across a lifespan: Aspects of acquisition, maturity and loss, K. Hyltenstam and L. Obler (eds.), 13-40. Cambridge: Cambridge University Press.

Müller, N. and A. Hulk 2001. "Cross-linguistic influence in bilingual first language acquisition: Italian and French as recipient languages." Bilingualism: Language and Cognition 4 (1): 1-21.

Muysken, P. 2000. Bilingual Speech. A typology of Code-Mixing. Cambridge: Cambridge University Press.

Paradis, J. and F. Genesee 1995. "Language differentiation in early bilingual development." Journal of Child Language 22: 611-631.

Schwartz, B. D. 2003. "Child L2 acquisition: paving the way." In Proceedings of the $27^{\text {th }}$ Annual Boston University Conference on Language Development, B. Beachley, A. Brown and F.Colin (eds.), 26-50. Somerville, MA: Cascadila Press.

Schwartz, B. D. 2004. "Why Child L2 Acquisition?" In The proceedings of GALA 2003, J. Van Kampen J. and S. Baauw (eds), 47-66. LOT Occasional Series.

Sorace, A. 2005. "Selective optionality in language development." In L. Cornips and K. Corrigan (eds), 55-80. Syntax and Variation. Reconciling the Biological and the Social. Current Issues in Linguistic Theory. Amsterdam/Philadelphia: John Benjamins.

Unsworth, S. I'LL ADD THE REFS FOR MY WORK (GALANA PAPER AND BU 2003) Van Berkum, J.J.A. (1996). The psycholinguistics of grammatical gender: Studies in language comprehension and production. Doctoral Dissertation, Max Planck Institute for Psycholinguistics. Nijmegen, The Netherlands: Nijmegen University Press

Velde, M. van der 2003. "Déterminants et pronoms en néerlandais et en français: syntaxe et acquisition." Thèse de doctorat Paris 8 http://umr7023.free.fr 
Velde, M. van der 2004. "L'acquisition des déterminants en L1: une étude comparative entre le français et le néerlandais". Acquisition et Interaction en Langue Etrangère 21: 9-46.

White, L. et al. 2001 "The status of abstract features in interlanguage: gender and number in L2 Spanish.” BUCLD 25: 792-802

Van Zonneveld R. 1992. "Het jonge hoofd - De Righthand Head Rule bij kinderen van 4 tot 7 jaar." De Nieuwe Taalgids 85 (1): 37-49.

Zuckerman, S. 2001. The acquisition of "optional" movement. PhD Groningen University.

Figure 1: the singular and plural definite and demonstrative determiners in Dutch

\begin{tabular}{|l|l|l|l|l|}
\hline & sef. det. & def. det. & dem. det & dem. det. \\
& singular & plural & singular & plural \\
\hline neuter noun & het & de & dat 'that' & die 'those' \\
& & & dit 'this' & deze 'these' \\
\hline non-neuter noun & de & de & die 'that' & die 'those' \\
& & & deze 'this' & deze 'these' \\
\hline
\end{tabular}


Figure 2: The subjects' age and language background

\begin{tabular}{|c|c|c|c|c|}
\hline \multirow[t]{10}{*}{ young } & \multicolumn{2}{|c|}{ 2L1/L2, $\mathrm{n}=8$} & \multicolumn{2}{|c|}{ L1 Dutch, $n=2$} \\
\hline & name & age 'other language' & name & age \\
\hline & Youssra & 3;0 Moroccan Arabic/Berber & Patrick & $3 ; 5$ \\
\hline & Joseph & 3;2 Moroccan Arabic/Berber & Joyce & $3 ; 9$ \\
\hline & Romy & $3 ; 2$ Sranan & & \\
\hline & Soraya & 3;3 Moroccan Arabic/Berber & & \\
\hline & \multicolumn{4}{|c|}{ Anthony 3;5 Sranan } \\
\hline & Nicole & $3 ; 6$ French & & \\
\hline & Jehiel & 3;9 Akan/Ewe & & \\
\hline & Stefano & 3;10 Sranan & & \\
\hline \multirow[t]{4}{*}{ middle } & \multicolumn{2}{|c|}{ 2L1/L2, $n=3$} & \multicolumn{2}{|c|}{ L1 Dutch, $n=3$} \\
\hline & Daphne & 4;11 Akan/Ewe & Ravian & $5 ; 2$ \\
\hline & Serwa & 5;0 Akan/Ewe & Thom & $5 ; 2$ \\
\hline & Damien & 5;2 Russian-Sranan & Jesse & $5 ; 2$ \\
\hline \multirow[t]{4}{*}{ old } & \multicolumn{2}{|c|}{ 2L1/L2, $n=3$} & \multicolumn{2}{|c|}{ L1 Dutch, $\mathrm{n}=1$} \\
\hline & Dilek & $9 ; 3$ Turks & Serge & $9 ; 6$ \\
\hline & Samir & 10;2 Moroccan Arabic/Berber & & \\
\hline & Nabil & 10;5 Moroccan-Arabic/Berber & & \\
\hline
\end{tabular}


Table 1: The determiner production when the input contained a non-neuter noun with the definite article de

\begin{tabular}{|c|c|c|c|c|c|}
\hline \multirow{2}{*}{$\begin{array}{l}\text { input de } \\
\text { non-neuter }\end{array}$} & & \multicolumn{2}{|c|}{ monolinguals } & \multicolumn{2}{|c|}{ bilinguals } \\
\hline & response & & & & \\
\hline young & & $\mathrm{n}=2$ & & $\mathrm{n}=8$ & \\
\hline \multirow[t]{6}{*}{$3 ; 0-3 ; 10$} & de/die/deze & 96 & $63 \%$ & 223 & $36 \%$ \\
\hline & het/dit/dat & 2 & $1 \%$ & 5 & $.8 \%$ \\
\hline & $\varnothing$ & 29 & $19 \%$ & 274 & $44 \%$ \\
\hline & een & 19 & $12 \%$ & 80 & $13 \%$ \\
\hline & other & 6 & $4 \%$ & 43 & $7 \%$ \\
\hline & & \multicolumn{2}{|c|}{152 total } & \multicolumn{2}{|c|}{625 total } \\
\hline middle & & $\mathrm{n}=3$ & & $\mathrm{n}=3$ & \\
\hline \multirow[t]{6}{*}{$5 ; 0-5 ; 2$} & de/die/deze & 94 & $90 \%$ & 66 & $55 \%$ \\
\hline & het/dit/dat & 2 & $2 \%$ & 0 & $0 \%$ \\
\hline & $\varnothing$ & 1 & $1 \%$ & 29 & $24 \%$ \\
\hline & een & 4 & $4 \%$ & 11 & $9 \%$ \\
\hline & other & 3 & $3 \%$ & 13 & $11 \%$ \\
\hline & & \multicolumn{2}{|c|}{104 total } & \multicolumn{2}{|c|}{119 total } \\
\hline old & & $\mathrm{n}=1$ & & $\mathrm{n}=3$ & \\
\hline \multirow[t]{6}{*}{$9 ; 3-10 ; 5$} & de/die/deze & 24 & $92 \%$ & 135 & $94 \%$ \\
\hline & het/dit/dat & 0 & & 0 & \\
\hline & $\varnothing$ & 1 & & 6 & $4 \%$ \\
\hline & een & 1 & & 0 & \\
\hline & other & 0 & & 2 & $1 \%$ \\
\hline & & \multicolumn{2}{|c|}{26 total } & \multicolumn{2}{|c|}{143 total } \\
\hline
\end{tabular}


Table 2: The determiner production when the input contained a neuter noun with the definite article het

\begin{tabular}{|c|c|c|c|c|c|}
\hline \multirow{2}{*}{$\begin{array}{l}\text { input het } \\
\text { neuter }\end{array}$} & & \multicolumn{2}{|c|}{ monolinguals } & \multicolumn{2}{|c|}{ bilinguals } \\
\hline & response & & & & \\
\hline young & & $\mathrm{n}=2$ & & $\mathrm{n}=8$ & \\
\hline \multirow[t]{6}{*}{$3 ; 0-3 ; 10$} & het/dit/dat & 3 & $11 \%$ & 17 & $13 \%$ \\
\hline & de/die/deze & 19 & $70 \%$ & 32 & $24 \%$ \\
\hline & $\varnothing$ & 2 & $7 \%$ & 67 & $49 \%$ \\
\hline & een & 2 & $7 \%$ & 13 & $9 \%$ \\
\hline & other & 1 & $4 \%$ & 7 & $5 \%$ \\
\hline & & \multicolumn{2}{|c|}{27 total } & \multicolumn{2}{|c|}{136 total } \\
\hline middle & & $\mathrm{n}=3$ & & $\mathrm{n}=3$ & \\
\hline \multirow[t]{6}{*}{$5 ; 0-5 ; 2$} & het/dit/dat & 27 & $77 \%$ & 8 & $17 \%$ \\
\hline & de/die/deze & 5 & $14 \%$ & 17 & $37 \%$ \\
\hline & $\varnothing$ & 1 & & 5 & $11 \%$ \\
\hline & een & 0 & & 5 & $11 \%$ \\
\hline & other & 2 & $6 \%$ & 11 & $24 \%$ \\
\hline & & \multicolumn{2}{|c|}{35 total } & \multicolumn{2}{|c|}{46 total } \\
\hline old & & $\mathrm{n}=1$ & & $\mathrm{n}=3$ & \\
\hline \multirow[t]{6}{*}{$9 ; 3-10 ; 5$} & het/dit/dat & 9 & $90 \%$ & 16 & $39 \%$ \\
\hline & de/deze/die & 1 & & 18 & $44 \%$ \\
\hline & $\varnothing$ & 0 & & 5 & $12 \%$ \\
\hline & een & 0 & & 1 & $2 \%$ \\
\hline & other & 0 & & 1 & $2 \%$ \\
\hline & & \multicolumn{2}{|c|}{10 total } & \multicolumn{2}{|c|}{41 total } \\
\hline
\end{tabular}


Figure 3: Variation in response with respect to the gender of definite article of the neuter noun meisje 'girl'

stimulus: het meisje 'the girl'

response:

de meisje

het meisje

age

2L1/L2

young

French

$\sqrt{ }$

young

Sranan

$\sqrt{ }$

young

Arabic/Berber

$\sqrt{ }$

young

Akan/Ewe

$\sqrt{ }$

middle

Akan/Ewe

$\sqrt{ }$

old

Arabic/Berber

$\sqrt{ }$

young

Sranan

young

Sranan

middle

Akan/Ewe

old

Arabic/Berber

old

Turks

young

Arabic/Berber

$\sqrt{ }$

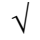

middle

Sranan 
Figure 4: the Dutch relative pronoun

\begin{tabular}{lll}
\hline & singular & plural \\
neuter noun antecedent & $d a t$ & die \\
non-neuter noun antecedent & die & die \\
\hline
\end{tabular}


Table 3: The relative pronoun production (completion without repetition) when the input contained a non-neuter noun

antecedent non-neuter

response

MONOLINGUALS

$3 ; 0-3 ; 10$

young

$\mathrm{N}=2 \quad$ ABS $\quad$ PROP.

Ø 18

.44

die

21

.51

dat 0

other 2

total 41

$4 ; 11-5 ; 2$

middle

$\mathrm{N}=3$

$\varnothing \quad 0$

die 42

1

dat 0

other

total 42

$9 ; 3-10 ; 5$

old

$\mathrm{N}=1$

die

12

dat 0

total 12

\section{BILINGUALS}

$\mathrm{N}=8 \quad$ ABS.

PROP.

69

.57

48

.39

1

4

122

$\mathrm{N}=3$

\section{4}

.49

20

.41

1

4

49

$\mathrm{N}=3$

35

.92

3

38 
Table 4: The relative pronoun production (completion without repetition) when the input contained the neuter noun dit meisje 'this girl'

\begin{tabular}{|c|c|c|c|c|c|c|c|c|c|}
\hline \multirow{2}{*}{\multicolumn{2}{|c|}{$\begin{array}{l}\text { antecedent neuter } \\
\text { het meisje 'the girl' }\end{array}$}} & \multicolumn{8}{|c|}{ response (completion) } \\
\hline & & MONO & LINGUAI & & & BILIN & JALS & & \\
\hline \multirow[t]{7}{*}{$3 ; 0-3 ; 10$} & young & $\mathrm{N}=2$ & ABS. & PROP. & & $\mathrm{N}=8$ & ABS. & & PROP. \\
\hline & & & $\varnothing$ & 8 & .42 & & & 25 & \\
\hline & & & & & & & & & \\
\hline & & die & 9 & .47 & & & 13 & & .30 \\
\hline & & dat & 2 & .11 & & & 2 & & \\
\hline & & other & 0 & & & & 3 & & \\
\hline & & total & 19 & & & & 43 & & \\
\hline \multirow[t]{6}{*}{$4 ; 11-5 ; 2$} & middle & $\mathrm{N}=3$ & & & & & $\mathrm{~N}=3$ & & \\
\hline & & $\varnothing$ & 2 & & & & 14 & & .78 \\
\hline & & die & 4 & .29 & & & 3 & & .17 \\
\hline & & dat & 7 & .50 & & & 0 & & \\
\hline & & other & 1 & & & & 1 & & \\
\hline & & total & 14 & & & & 18 & & \\
\hline \multirow[t]{5}{*}{$9 ; 3-10 ; 5$} & old & $\mathrm{N}=1$ & & & & & $\mathrm{~N}=3$ & & \\
\hline & & $\varnothing$ & 0 & & & & 0 & & \\
\hline & & die & 1 & & & & 3 & & .43 \\
\hline & & dat & 5 & .83 & & & 4 & & .57 \\
\hline & & total & 6 & & & & 7 & & \\
\hline
\end{tabular}


Figure 5: Individual grammars containing the form of the definite determiner and relative pronoun concerning neuter noun meisje 'the girl'

\begin{tabular}{|c|c|c|c|c|c|}
\hline & de meisje & het meisje & meisje die & meisje dat & \\
\hline Grammar 1 & $\sqrt{ }$ & - & $\sqrt{ }$ & - & $\mathrm{n}=2$ \\
\hline Grammar 2 & $\sqrt{ }$ & - & $\sqrt{ }$ & $\sqrt{ }$ & $\mathrm{n}=3$ \\
\hline Grammar 3 & $\sqrt{ }$ & $\sqrt{ }$ & $\sqrt{ }$ & - & $\mathrm{n}=2$ \\
\hline Grammar 4 & $\sqrt{ }$ & $\sqrt{ }$ & $\sqrt{ }$ & $\sqrt{ }$ & $\mathrm{n}=1$ \\
\hline Grammar 5 & $\sqrt{ }$ & $\sqrt{ }$ & - & $\sqrt{ }$ & $\mathrm{n}=2$ \\
\hline Grammar 6 & - & $\sqrt{ }$ & $\sqrt{ }$ & $\sqrt{ }$ & $\mathrm{n}=1$ \\
\hline Grammar 7 & - & $\sqrt{ }$ & - & $\sqrt{ }$ & $\mathrm{n}=2$ \\
\hline
\end{tabular}

NOT FOUND

\begin{tabular}{cccccc} 
& de meisje & het meisje & meisje die & \multicolumn{2}{c}{ meisje dat } \\
Grammar 8 & $\sqrt{ }$ & - & - & $\sqrt{ }$ & $\mathrm{n}=0$ \\
Grammar 9 & - & $\sqrt{ }$ & $\sqrt{ }$ & $\mathrm{n}=0$
\end{tabular}

